\title{
Knowledge, Attitudes and Perceived Barriers towards Scientific Research among Undergraduate Health Sciences Students in the Central Province of Saudi Arabia
}

\author{
Faisal Al-Nashmy Al-Shalawy ${ }^{1}$, Abdul Haleem ${ }^{2}$ \\ ${ }^{1}$ Dental Student, ${ }^{2}$ Department of Community Dentistry and Oral Epidemiology, Qassim University, College of \\ Dentistry, Saudi Arabia.
}

\section{ARTICLE INFO}

Received

Accepted

: 23/04/2014

Published

: 30/12/2014

: 25/03/2015

\section{KEYWORD}

Undergraduate Health Sciences

Students

Scientific knowledge

Attitudes

Research Participation

\section{ABSTRACT}

Introduction: Research training makes an important part of the present day health sciences curricula. Although a few research studies have been undertaken in gulf countries and Saudi Arabia about the knowledge and attitudes of health sciences students regarding research none has been reported from the central province of Saudi Arabia. Objective: The present study was conducted with the objectives of assessing the knowledge and attitudes of health sciences students in the universities of the central province of Saudi Arabia. The degree of involvement of students in research and the barriers to student's research activities were also explored. Method: The study design was cross-sectional that involved 435 medical, dental and pharmacy students in eleven health sciences colleges of five randomly selected universities in the central province of Saudi Arabia. The data were collected using an anonymous self-administered and validated questionnaire that was slightly modified and pilot tested for the present study. Result: The study participants had a mean knowledge score of $4.6 \pm 1.7$ out of a total of 10 and mean attitude score of $4.4 \pm 1.1$ out of 6 . The majority of students perceived shortage of time, lack of motivation and appreciation, and insufficient laboratory facilities the major barriers to the students' research activities. Moreover, only $6.9 \%$ ever published a research paper. Conclusion: The attitudes of the health science students towards research were mostly positive, but they had a low level of knowledge about scientific research. The study highlighted certain perceived barriers to undergraduate research activities.

(C) Medical Education Department, School of Medical Sciences, Universiti Sains Malaysia. All rights reserved.

CORRESPONDING AUTHOR: Faisal Al-Nashmy Al-Shalawy, Dental Student, Qassim University, College of Dentistry, Saudi Arabia. Email: faisal.shalawy@qudent.org

\section{Introduction}

Medical research training forms an important part of health sciences education [1]. It is essential to inculcate critical thinking and reasoning skills among undergraduate health sciences students. It is also imperative to develop a positive attitude among students towards scientific research from the beginning of their medical career [2-5]. Studies have shown that students' involvement in research is strongly associated with postgraduate research initiatives 
$[6,7]$. Nevertheless, the role of undergraduate research assistants has also been found important [8]. A cause of concern is that the number of scientists has declined over the past two decades and there is a dire need for more clinical as well as basic health science investigators [9].

Several studies have assessed attitudes towards and knowledge about scientific research among medical students in developed and developing countries [2, 3, 7,10-12]. A cross-sectional study conducted in medical schools of three universities in Saudi Arabia, Bahrain and Kuwait found that although the majority of the study subjects had positive attitudes towards scientific research, their knowledge score was on the lower side (mean: $3.6 \pm 1.7$ out of 10). The study highlighted certain barriers to undergraduate research such as shortage of time and lack of adequate mentoring perceived by the students [2].

Another study conducted among a group of Pakistani medical students reported a moderate level of knowledge about health research with about $80 \%$ of the students falling in the middle two quartiles of the knowledge score [3]. Similar findings about knowledge were reported in a study on first-year Croatian medical students [12], but the attitude score of the study subjects was much lower than that found in the latter study [3].

A study on Irish medical undergraduate students found that although the majority of students were well motivated to pursue research, heavy workload, financial difficulties, poor guidance and support from the medical school were reported to hinder the undergraduate medical students' research [4] These barriers were also reported in a study done earlier in Pakistan [11, $14]$.

A search of the medical literature through electronic data bases revealed just one study undertaken in gulf countries [2]. That study included only one out of 32 Saudi universities. In addition, it did not include dental and pharmacy students.
The objectives of the present study were to assess the knowledge about, attitudes towards and the perceived barriers to participation in scientific research among undergraduate health sciences students (medicine, dentistry, pharmacy) of both public and private universities of the central province in Saudi Arabia. In addition, actual degree of involvement of the students in research was explored in the study.

\section{Method}

\section{Research design}

The present study was a cross-sectional questionnaire-based study.

\section{Study setting}

Five universities in the central province of the Kingdom of Saudi Arabia were randomly selected using a lottery method. These universities had a total of eleven colleges educating health sciences students. For the sake of anonymity the names of the chosen universities have been abbreviated as A, B, C, D, and $\mathrm{E}$ in subsequent sections.

\section{Study participants}

All $7845^{\text {th }}$ year health sciences students enrolled in eleven colleges were eligible to participate in the study. The students not present on the day of the study and those not willing to fill in the questionnaire were excluded.

\section{Data collection methods}

The questionnaire was distributed among 582 students present on a week day with maximum average students' attendance as suggested by_the faculty members of the respective colleges. A total of 502 questionnaires were collected back after a week's time with a response rate of about $86 \%$.

A structured questionnaire developed and validated by Vodopivec et.al. [7] was adapted for the study. The questionnaire was slightly modified to achieve the objectives of the study. The modified questionnaire was reviewed by two medical educationists for the face and content validity. It was then pilot tested on 10 dental students to assess its reliability. The pilot testing 
revealed a Cronbach's alpha score of 0.68 of the modified questionnaire. The questionnaire was again modified and pilot tested on a group of 25 medical, dental and pharmacy students. The second test gave a Cronbach's alpha score of 0.73 of the final questionnaire.

The questionnaire used for the study consisted of the following sections:

a. Personal data: gender, GPA score, and parental educational status.

b. Knowledge about scientific research: Ten items of multiple options format were taken from the initial tool used by Vodopivec et. al [12] but three questions with difficult English phrases were modified based on the first pilot test results.

c. Attitudes towards scientific research: Six items with a Likert scale format with options ranging from strongly disagree (1) to strongly agree (5) were included.

d. Active involvement in scientific research: It was explored through five items with yes or no choices. Three questions were taken from Vodopivec's questionnaire while two new questions were added to investigate this domain.

e. The final component comprised of nine statements of Likert scale type about perceived barriers to participation in scientific research activities.

An introductory note was added in the questionnaire to inform the students about the purpose of the study and to ensure them about the confidentiality of data they provided. The ethical approval for the study was given by Dental Ethical Committee of the Dental Research Center (DRC) of Qassim University.

\section{Data analysis}

A total of sixty seven questionnaires with missing responses for more than two questions were excluded: 18 from the university A, 10 from B, 16 from C, 11 from D, and 12 from E. The remaining 435 questionnaires were subjected to data analysis using IBM SPSS statistics version 22.0. The correct response to a knowledge question was given a score of 1 while the incorrect response had zero score.
The results about the numerical variables were reported as mean and standard deviation while the categorical data were presented using proportions and percentages.

A result with a p-value of $<0.05$ was considered as statistically significant. The chi-square was used to compare proportions while comparisons of the mean scores were performed by independent t-test and Analysis of Variance (ANOVA) test.

\section{Result}

The study at the data analysis stage included 435 $5^{\text {th }}$ year students in eleven colleges of both public and private universities of the central province of KSA. Tables 1, 2, 3, 4 and 5 depict the university-wise distribution of the study parcipants according to gender, health sciences speciality, father and mother educational level and GPA score of the study subjects.

Table 1: Gender distribution of the study participants.

\begin{tabular}{lcc}
\hline & \multicolumn{2}{c}{ Gender, n (\%) } \\
\cline { 2 - 3 } University & Male & Female \\
\hline A (N=129) & $72(55.8)$ & $57(44.2)$ \\
B $(\mathrm{N}=141)$ & $75(53.2)$ & $66(46.8)$ \\
C $(\mathrm{N}=44)$ & $26(59.1)$ & $18(40.9)$ \\
D $(\mathrm{N}=35)$ & $22(62.9)$ & $13(37.1)$ \\
E $(\mathrm{N}=86)$ & $45(52.3)$ & $41(47.7)$ \\
\hline Total & $240(55.2)$ & $195(44.8)$ \\
\hline
\end{tabular}

Table 2: Specialties-wise distribution of the study participants.

\begin{tabular}{lccc}
\hline & \multicolumn{3}{c}{ Specialty, n (\%) } \\
\cline { 2 - 4 } University & Dentistry & Medicine & Pharmacy \\
\hline A (N=129) & $36(27.9)$ & $63(48.8)$ & $30(23.3)$ \\
B (N=141) & $38(27.0)$ & $63(44.7)$ & $40(28.4)$ \\
C $(N=44)$ & $0(0)$ & $44(100.0)$ & $0(0)$ \\
D ( $=35)$ & $14(40.0)$ & $0(0)$ & $21(60.0)$ \\
E ( $=86)$ & $47(54.7)$ & $0(0)$ & $39(45.3)$ \\
\hline Total & $135(31.0)$ & $170(39.1)$ & $130(29.9)$ \\
\hline
\end{tabular}


Table 3: Distribution of the study participants according to Father's educational status.

\begin{tabular}{lcccc}
\hline & \multicolumn{4}{c}{ Father Educational Status, n (\%) } \\
\cline { 2 - 5 } University & Illiterate & $\begin{array}{c}\text { Primary } \\
\text { School }\end{array}$ & $\begin{array}{c}\text { Secondary } \\
\text { School }\end{array}$ & $\begin{array}{c}\text { Colleague or } \\
\text { Higher }\end{array}$ \\
\hline A (N=129) & $0(0)$ & $21(16.3)$ & $49(38.0)$ & $59(45.7)$ \\
B (N=141) & $0(0)$ & $15(10.6)$ & $52(36.9)$ & $74(52.5)$ \\
C $(\mathrm{N}=44)$ & $3(6.8)$ & $11(25.0)$ & $15(34.1)$ & $15(34.1)$ \\
$D(N=35)$ & $0(0)$ & $2(5.7)$ & $8(22.9)$ & $25(71.4)$ \\
E (N=86) & $0(0)$ & $11(12.8)$ & $19(22.1)$ & $56(65.1)$ \\
\hline Total & $3(0.7)$ & $60(13.8)$ & $143(32.9)$ & $229(52.6)$ \\
\hline
\end{tabular}

Table 4: Distribution of the study participants according to Mothers' educational status.

\begin{tabular}{lcccc}
\hline & \multicolumn{4}{c}{ Maternal Educational Status, n (\%) } \\
\cline { 2 - 5 } University & Illiterate & $\begin{array}{c}\text { Primary } \\
\text { School }\end{array}$ & $\begin{array}{c}\text { Secondary } \\
\text { School }\end{array}$ & College or Higher \\
\hline A (N=129) & $0(0)$ & $15(11.6)$ & $73(56.6)$ & $41(31.8)$ \\
B (N=141) & $0(0)$ & $14(9.9)$ & $65(46.1)$ & $62(44.0)$ \\
C $(\mathrm{N}=44)$ & $0(0)$ & $4(9.1)$ & $24(54.5)$ & $16(36.4)$ \\
$D(N=35)$ & $5(14.3)$ & $2(5.7)$ & $16(45.7)$ & $12(34.3)$ \\
E (N=86) & $0(0)$ & $8(9.3)$ & $23(26.7)$ & $55(64.0)$ \\
\hline Total & $5(1.1)$ & $43(9.9)$ & $201(46.2)$ & $186(42.8)$ \\
\hline
\end{tabular}

Table 5: Distribution of the study participants according to GPA scores of students.

\begin{tabular}{lccc}
\hline University & \multicolumn{3}{c}{ GPA scores, n (\%) } \\
\cline { 2 - 4 } & $\mathbf{3 . 0}$-3.5 & $\mathbf{3 . 5 1} \mathbf{- 4 . 0}$ & $\mathbf{4 . 0 1 - 5 . 0}$ \\
\hline A (N=129) & $5(3.9)$ & $83(64.3)$ & $41(31.8)$ \\
B (N=141) & $2(1.4)$ & $92(65.2)$ & $47(33.3)$ \\
C $(\mathrm{N}=44)$ & $8(18.2)$ & $22(50.0)$ & $14(31.8)$ \\
D $(\mathrm{N}=35)$ & $0(0)$ & $18(51.4)$ & $17(48.6)$ \\
E $(\mathrm{N}=86)$ & $4(4.6)$ & $41(47.7)$ & $41(47.7)$ \\
\hline Total & $19(4.4)$ & $256(58.8)$ & $160(36.8)$ \\
\hline
\end{tabular}

\section{Discussion}

The study under discussion highlighted moderately positive attitudes towards and a low level of knowledge about scientific research among Saudi students. Similar findings were reported by by Tarek et. al (2013) in a study on 432 students in three Arab universities [2]. In that study the mean knowledge score was lower than found in the present study (3.6 \pm 1.7 vs. $4.6 \pm$ 1.7 out of 10 respectively). However in both studies the majority of the students had positive attitudes towards scientific research. That study, like the present study, also found shortage of time and a lack of adequate mentoring to be significant barriers to undergraduate research. One of the largest studies that assessed the attitude of undergraduate medical students towards scientific research was conducted by Hren et. al (2004) in Croatia [7]. This study involved 932 students, with a response rate of $58 \%$ and showed that the average score for attitude towards scientific research was quite good (Mean score 166 \pm 22 out of a maximum of 225), Knowledge score was relatively poor (Mean score of $3.2 \pm 1.7$ on 8). A study reported from Pakistan by Khan et. al showed mean scores scale of $49.0 \%$ and $53.7 \%$ of the study subjects had the correct knowledge and positive attitudes towards health related research respectively [3]. On the other hand $70-80 \%$ of participants in the present study exhibited positive attitudes towards research a while the percentage of students giving right answers to various knowledge questions ranged from 34 to $57 \%$.

The present found that despite having positive attitudes, the students reported a low level of active participation in scientific research. It shows the importance of knowledge about and perceived barriers to scientific research. A study conducted by Burgoyne et. al has also demonstrated that the research competence of the medical undergraduate students does not align closely with their level of motivation for research and the students' incompetence stems from a lack of understanding of the concept of 
translational research [4]. Furthermore, they reported a lack of students' awareness about the research activity being undertaken by their teachers and mentors augments their incompetence.

Although the relationship between the year of undergraduate education and knowledge/ attitudes towards research has been studied in previous studies, the study under discussion did not explore this factor due to economic and logistic problems. The study by Khan et. al showed that students' knowledge and attitude towards health research significantly improved with increasing years of education at medical school [3]. This according to the authors signifies a relatively satisfactory contribution of medical curriculum in developing research skills among medical students through well-structured intensive training. Similarly a longitudinal study by Vukaklija et. al. showed a definite increase in the attitude scores as the students moved from the first year to the sixth year of the undergraduate course [15]. However, in the study by Tarek et. al (2013) third year students had a higher attitude scores compared to 4th and 5th years [2].

In line with the finding of the study by Tarek et. al (2013) the present study found no significant effect of gender on students' attitudes to research. Khan et. al (2006) also found gender a non-significant predictor of knowledge about health research in their study. However, male students had a significantly higher mean score on the attitude scale than the females [3].

The literature search revealed that the study under discussion was the first one to compare different Saudi universities and specialities with regard to the undergraduate students' knowledge, attitudes, behaviour and perceived barriers to scientific research.

\section{Conclusion}

Health sciences students at five Saudi universities in central province demonstrated moderately high attitudes towards but moderate to low level of knowledge about scientific research. This may be associated with perceived barriers to the students' participation in research highlighted by the study. These barriers need to be addressed to improve the undergraduate research activity in the study area.

\section{Recommendations}

- Review undergraduate curricula and Include research methodology and biostatistics as essential subjects in curricula of health sciences students in all universities.

- Make participation in scientific research activities a requirement for graduation .

- Create a research culture by celebrating research days, organizing conferences and conferring awards to outstanding researches.

- Offer proper laboratory facilities to health sciences students in order to promote labbased research.

- Encourage faculty to take an active interest in all aspects of students' research including study design, data collection, statistical analysis and preparation of scientific manuscripts.

- Involve students in faculty research projects.

- Conduct student research workshops and Introduce innovative methods to teach research methodology to undergrads.

- Publish scientific journals with student research as the primary content.

\section{Limitations}

All five universities might have significant differences concerning research component in their undergraduate curricula. This aspect was not taken into account while doing this comparative study. Regarding the perceived barriers to research, faculty input could have been a valuable addition which was not explored in the present study.

\section{Acknowledgement}

The author would like to acknowledge the valuable task performed by his colleagues in data collection in the Colleges of Medicine, Dentistry 
and Pharmacy at Qassim University in AlQassim, King Saud bin Abdul-Aziz University for Health Sciences in Al-Riyadh, King Saud University in Al-Riyadh, Buraidah Private Colleges in Al-Qassim, Riyadh Colleges of Dentistry and Pharmacy in Al-Riyadh.

\section{Reference}

1. Scaria V: Whisking Research into Medical Curriculum: The need to integrate research in undergraduate medical education to meet the future challenges. Calicut Medical Journal 2004,2:e1.

2. Amin, T., Kaliyadan, F., Al Qattan, E., Al Majed, M., Al Khanjaf, H., \&Mirza, M. (2012). Knowledge, attitudes and barriers related to participation of medical students in research in three Arab Universities. Education In Medicine Journal, 4(1). DOI:10.5959/eimj.v4i1.7

3. Khan H, Khawaja MR, Rauf MA, Fatmi Z. Knowledge and attitudes about health research amongst a group of Pakistani medical students. BMC Med Educ. 2006; 6: 54.

4. Burgoyne LN, O'Flynn S, Boylan GB. Undergraduate medical research: the student perspective. Med Educ Online. 2010,10;15. doi: 10.3402/meo.v15i0.5212.

5. Shewan LG, Glatz JA, Bennett C, Coats AJ: Contemporary (postwills) survey of the views of Australian medical researchers: importance of funding, infrastructure and motivators for a research career. Med J Aust 2005, 183:606-11.

6. Reinders JJ, Kropmans TJ, CohenSchotanus J: Extracurricular Research experience of medical students and their scientific output after graduation. Med Educ 2005, 39:237.

7. Hren D, Lukić IK, Marušić A, Vodopivec I, Vujaklija A, Hrabak M, Marušić M: Teaching research methodology in medical schools: students' attitudes towards and knowledge about science. Med Educ 2004, 38:81-86.

8. Wyngaarden J: The Clinical Investigator as endangered spe-cies. N Eng J Med 1979, 301:1254-1259.
9. Pasko T, Smart D: Physician Characteristics and Distribution in the US.2005 Edition American Medical Association Press; 2004.

10. Segal S, Lloyd T, Houts PS, Stillman PL, Jungas RL, Greer RB. The association between students' research involvement in medical school and their postgraduate medical activities. Acad Med. 1990;65:530-533.

11. Ejaz K, Shamim MS, Shamim MS, Hussain SA. Involvement of medical students and fresh medical graduates of Karachi, Pakistan in research. J Pak Med Assoc. 2011;61:115-20.

12. Vodopivec I, Vujaklija A, Hrabak M, Lukiæ IK, Marušiæ A, Marušiæ M. Knowledge about and attitudes towards science of first year medical students. Croat Med J. 2002;43:58-62.

13. Park SJ, Liang MM, Sherwin TT, McGhee CN. Completing an intercalated research degree during medical undergraduate training: barriers, benefits and postgraduate career profiles. N Z Med J. 2010;123:2433.

14. SaniyaSabzwari, SamreenKauser, Ali Khan Khuwaja. Experiences, attitudes and barriers towards research amongst junior faculty of Pakistani medical universities. BMC Medical Education 2009, 9:68 doi:10.1186/1472-6920-9-68

http://www.biomedcentral.com/14726920/9/68

15. Vujaklija A, Hren D, Sambunjak D, Vodopivec I, Ivanis A, Marusić A, et. al. Can teaching research methodology influence students' attitude toward science? Cohort study and nonrandomized trial in a single medical school. J Investig Med.2010;58:282-6. 